\title{
Towards an Integrated Approach in Knowledge Management in the Creative Industry
}

\author{
Corazon Gaanan Anzano and Marites A. Khanser
}

\begin{abstract}
The study is an assessment of the knowledge management system used by the creative enterprises in Cebu, Philippines to identify, measure, manage and develop intellectual capital. It is a descriptive research. The study used Pearson's correlation to test the strength of association among the variables namely: intellectual capital inventory, elicitation, generation, documentation, utilization, retention, maintenance and enrichment audit. Findings revealed that the 25 enterprises have a knowledge management system embedded in the firm. There was conscious effort to manage the knowledge flow, however, problems were encountered due to its intangible nature. The study presents the CGA Knowledge Flow Management Model which advocates for a firm to imbibe a knowledge-sharing culture and such sharing must reach up to reciprocity. The study calls for a paradigm shift in the mindset of knowledge workers who are the source of creativity and competitive advantage for the firm.
\end{abstract}

Index Terms-Creative industry, intellectual capital, intellectual property rights, knowledge management.

\section{INTRODUCTION}

The third millennium is characterized as a knowledge economy where knowledge is the key resource. It is not enough to produce products or services at low cost. With the rise of China that can easily produce cheaper goods than any country can, the sustainable strategy is to produce products or services that are either innovative or tailor-made for individual customers. This kind of competition requires a workforce with strong analytical skills.

The firm's brain power must be reflected in the products offered and services rendered which is an output of an intensive intellectual discourse within the business organization geared towards responding to changes in the environment. The intellectual discourse among employees creates economic value through the birth of ideas either in the form of a product/service concept, an innovative process, product brands, product concept, product positioning, marketing strategies, customer relations and crisis management, to name a few.

Knowledge has become a valuable entity, an indispensable tool in businesses today. It is a real asset that can provide a sustainable competitive advantage to the firm. It is by nature

Manuscript received April 20, 2013; revised June 21, 2013. The study was funded by the Commission on Higher Education of the Republic of the Philippines through a Dissertation Grant.

C. G. Anzano is with the Department of Economics and Business Administration of the University of San Carlos, Cebu, Philippines (e-mail: cora.gaanan@yahoo.com).

M. A. Khanser is with the Department of Business Administration of the University of San Carlos, Cebu, Philippines (e-mail: mkhanser2003@yahoo.com.). intangible. Its intangibility is expressed in a variety of types and formats called intellectual capital (IC). Knowledge produces IC such as intellectual property rights, product brands, franchise, business relationship, and others.

The firm, then, needs to quantify knowledge and put value into it. IC is intangible and its value can be estimated indirectly by foreseeing its output value. Valuation is needed to support management decision in the allocation of investment into developing and acquiring knowledge. Knowing the source of IC and why it varies will help management make decisions and set strategies through the development of their intangibles.

If IC is the company's competitive edge which can become a determinant to its success or failure, then, it must be able to identify, measure, manage and develop this asset. Management efforts have to focus on IC and their use. The task is to determine which one needs to be strengthened or acquired in order to succeed. This management effort to maximize the potentials of knowledge is called knowledge management.

Considering the value of IC to the firm, there is a need, then, to assess how the knowledge management system of the firm affects the people and the strategy it employed to create value. A knowledge management system (KMS) must be in place to ensure that IC has a positive impact in the business organization. But the question is: is there a knowledge management system in the firm? If there is, is it producing the right results that will translate to improving business performance?

The task of management is to motivate, manage and control the knowledge worker and optimize his creativity within the firm's organizational disciplines and constraints.

The objectives of this paper were, first, to determine IC of a business organization, measure its value and identify its valuation process, and second, to recommend a knowledge management model that best fit the creative industry of Metropolitan Cebu, Philippines.

The creative industry is research-intensive, highly innovative and to a large extent dependent on its IC to run its business. Two factors that create and produce IC are the knowledge workers and the working environment that must be conducive to sharing and discussion. By the very nature of its industry, management of this IC is a key factor to generate creative works that would give it its competitive advantage.

In a news article released in the local Cebu daily, The Freeman, last October 12, 2010, Andrew Senior, head for creative economy unit of the British Council, suggested that Cebu should maximize its creative industry and make it one of the economic drivers for the province.

This then led to the establishment of the Creative Cebu Council, Inc., a non-stock, non-profit, industry association 
composed of creative entrepreneurs representing various sectors who have banded together to promote, develop and champion the creative industries in Cebu. It is represented by clusters in the Creative Industries sector comprising the following: advertising \& communications, theatre and performing arts, visual arts, music, design, architecture, literature \& publishing, photography, cinema \& audio-visual, culinary arts and the multi-media arts. Design services include fashion designing and arts and craft design.

If the creative industry is to be the engine of growth for the Cebu economy then IC, which is an indicator for its success, must be given emphasis. But acknowledgement of its importance is not enough. It must also be managed and results should be obtained and measured. From a business point of view, appropriate management of IC is recommended. There is also a need to examine the impact of a firm's knowledge management system on productivity, or to investigate the impact of different knowledge sharing incentive schemes on knowledge users. There is a need to understand how these systems affect people and strategy.

\section{RESEARCH PROBLEM}

Given the importance of IC in the creative industry, the study sought to do the following:

1) Determine the current state of the intellectual capital of Metro Cebu's creative enterprises;

2) Determine how the creative enterprises value their intellectual capital;

3) Describe knowledge management in the creative enterprises;

4) Determine if there is a significant need to improve knowledge management in Metro Cebu's creative industry;

5) If found significant, to propose a knowledge management model.

\section{LITERATURE REVIEW}

Brooking (1996) proposed a measurement model to help capture the value of IC. She classified IC in four components: market assets, assets centered on humans, intellectual property and infrastructure assets [1].

Market assets are intangibles related to the market such as clients' loyalty, brands, distribution channel, contracts and advertisement. Assets centered on humans are composed of the experience, creativity, solving problems ability, entrepreneurship, and management skills of its employees. Infrastructure assets are technology, methodologies, corporate culture, communication systems, etc. Intellectual property is know-how, trade secrets, trademarks, patents and design rights.

The International Accounting Standard (IAS) \#38 prescribed the accounting treatment for intangible assets [2]. IAS \# 38 defined intangible asset as an identifiable non-monetary asset without physical substance. It must satisfy the following criteria: it is identifiable, it can be controlled, it is probable that future benefits specifically attributable to the asset will flow to the business enterprise, and cost can be reliably measured. If an item does not meet the definition of an intangible asset, then, it shall be reported as an expense in the financial statements.

Mouritsen (2004) claimed that the International Accounting Standards Committee and its national counterparts faced a challenge in setting standards for intellectual capital disclosure [3]. The challenge was attributable to the lack of tangible collaterals to measure intangible assets. Voluntary disclosure is the only solution in the short term.

O'Reagan (2003) emphasized that if efforts are not made to incorporate the value of intangibles such as internal structures, external structures and employee competencies into a formalised reporting framework then there exists a significant risk that management reporting and financial statements will become irrelevant [4]. Unless the accountancy profession responds proactively to this challenge, it risks losing its current privileged and traditional position in the organisational order.

Gallupe (2000) advocated for the development of a knowledge management system in a business organization to help solve new and novel problems [5]. He emphasized that the competitive advantage of a company in today's knowledge economy was not from its market position but must come from the difficulty of its competitors to replicate knowledge assets that it has and the manner in which it was deployed. He further emphasized that knowledge management is now a mandate for all business organizations regardless of whether they are private or public, big or small, services, manufacturing or resources. A knowledge management system must be imbedded in all business organizations. He defined knowledge management system as the tool and technique that support knowledge management practices in business organizations. The system is designed and developed to give decision makers and users the knowledge needed to make appropriate business decisions.

\section{CONCEPTUAL FRAMEWORK}

The study traced the management and valuation of intellectual capital in a business organization. Fig. 1 is the conceptual framework of the study. The study used the definition of Brooking (1996) where intellectual capital is composed of four components: intellectual property assets, human resource assets, market assets and infrastructure assets [1]. The study hypothesizes that there is a direct relationship between and among the four components with intellectual capital. This relationship is depicted by the broken line around the four components.

The study used the intellectual capital audit and valuation model by Young (2004) to validate the existence of IC [6]. The audit model entailed two steps: 1) intellectual capital inventory which refers to the identification and recognition of the intellectual capital that the firm has including how it was generated and elicited from its employees and company activities; 2) intellectual capital documentation which includes how it was utilized, retained and maintained and intellectual capital enrichment which determined how intellectual assets is continuously enriched, intensified and strategized.

The business organization is believed to have a knowledge management system (KMS) that will enhance and maintain the management of intellectual capital. The study 
hypothesized further that the proper management and valuation of IC is expected to result to a positive effect on business performance which is translated in three ways: improvement in financial position of the company, increase productivity of employees and a positive impact on attitude of employees.

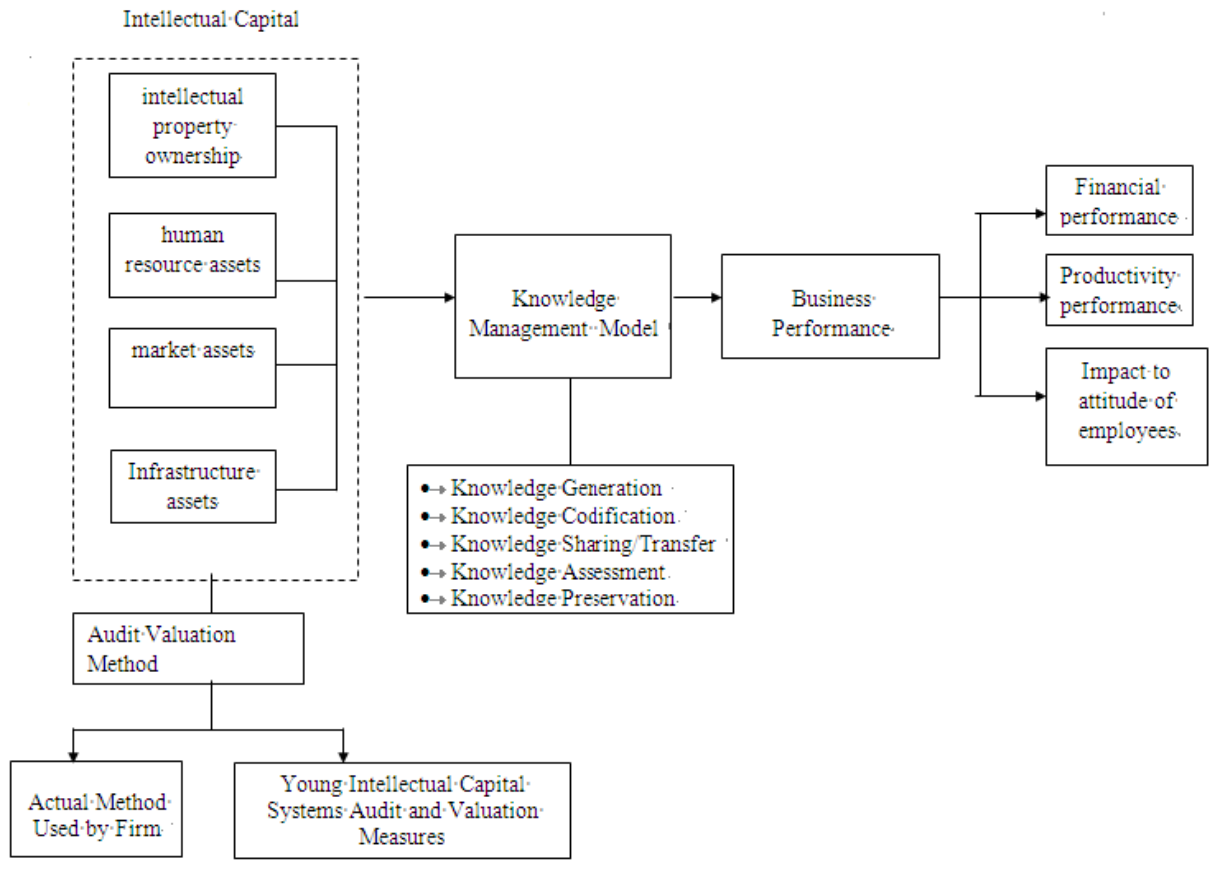

Fig. 1. Conceptual framework.

\section{RESEARCH METHOD}

The study focused on the creative industries in Metropolitan Cebu. In 2008, Metropolitan Cebu was recognized by British Council as the Creative Capital of the Philippines and chose Cebu to form part of its regional project on Creative Cities for East Asia. In the same year, the Cebu Provincial Office of the Department of Trade and Industry (DTI) identified the creative industry as one of the priority sectors for development and promotion. In 2011, Cebu's economy contributed $20 \%$ to the Philippines' gross domestic product, signifying that it is an important player in the Philippine economy.

Twenty-five (25) creative enterprises were interviewed. Fifteen of them were participants to the first Creative Industry Summit held in Cebu City, Philippines last July 21 22, 2011. The summit was hosted by the Cebu Chamber of Commerce, Inc. and the Department of Trade and Industry Cebu Province. as part of the Cebu Business Month celebration. The theme of the summit was: Entrepreneurship Interface with Creativity and Innovation. The summit brought together 249 participants from various sectors of the Cebu community: academe, business and government.

The 25 enterprises were classified by cluster based on the definition of the Cebu Creative Council namely: advertising $\&$ communications, theatre and performing arts, visual arts, music, architecture, design services, literature \& publishing, photography, cinema \& audio-visual, culinary arts and the multi-media arts. Design services include fashion and arts and craft. Majority of the respondents, 36\%, were from design services.

The company-respondents were the Chief Executive Officer (40\%), and person in supervisory position $(60 \%)$ who is presumed to have a comprehensive knowledge of the management of the business. This enabled the researcher to go on in-depth interview regarding the management of the firm. Data was gathered thru semi structured interviews with 25 top management officials of companies classified as a creative enterprise. On site observation of the company was also done by the researcher and secondary data that were provided by the company respondents was used. Key informant interview approach was used to get an in-depth view of the respondents on the knowledge management strategies they employed in their business. This enabled the researcher to have case studies of how knowledge management is done in the creative enterprises, their best practices and challenges encountered.

\section{RESULTS AND DisCUSSIONS}

Intellectual Capital of Creative Enterprises. Intellectual capital is defined to have four components: human resource assets, market assets, infrastructure assets and intellectual property assets. Findings showed that only 8 or $32 \%$ had intellectual property (IP) rights. The 8 company respondents belonged to the culinary arts, new media, architecture, advertising and design services cluster. For the 17 companies $(68 \%)$ who did not have intellectual property rights, 6 or $24 \%$ had intentions to apply. All of them belonged to the design services cluster. The application for intellectual property rights were being processed at the time of the interview and were in different phases of the application process. The remaining 11 or $44 \%$ of the respondents admitted that they did not have any intellectual properties in the form of trade secrets, trademarks, patents and design rights that was uniquely and originally theirs that merits registration.

Empirical Test of Young's Intellectual Capital Systems Audit Model. The study conducted an IC audit for three reasons: first, to verify the existence of IC and its four components; second, to appraise its utility and third, to 
evaluate the efficiency of use. The audit is based on the premise that IC in itself is intangible and can be manifested only if it is managed and when output is produced. Therefore, to test its existence, the audit was done on the IC system from where it was born and continued to exist within the business establishment. The components of IC create value only if there is interaction among them.

The study used the audit model authored by Dr. Felina Young (2004) [6] which looked into two aspects: IC inventory and IC documentation. The respondents were asked to rate the extent of effort of management in managing of IC in the company for the past three years. The rating scale was from 1 to 5 with 1 as no extent and 5 as very great extent.

The IC inventory audit was done in three sections: the IC inventory audit which involved the identification and recognition of the intellectual capital in the firm; the IC elicitation audit which determined the extent to which the company is able to draw out IC from individuals or groups of individuals; and IC generation audit which traced how the company is able to create IC by hiring the best individuals, motivating and optimizing their potentials and providing them a milieu of empowerment.

The section on IC documentation determined the extent to which the company was able to document IC by registering all copyrights, patents, trademarks and trade secrets, creating a database, systematizing and standardizing information and structure knowledge for cross boundary sharing. The section on IC utilization audit evaluated the extent to which the company is able to apply and handle IC assets in terms of structure, systems, methodologies, functional processes, job enlargement, job enrichment, specific "know-hows" and employee development. The section on IC retention audit evaluated the extent to keep the owners and main contributors of IC in the organization. The section on IC maintenance audit evaluated the extent to which the company is able to preserve and keep its IC assets. The section on IC enrichment audit evaluated the extent to which the company is able to enhance and reinforce IC assets thru knowledge leadership, synergistic collaboration and cutting edge training.

TABLE I: EXTENT OF EFFORT TO MANAGE INTELLECTUAL CAPITAL

\begin{tabular}{|c|c|c|c|c|}
\hline Section & Purpose & Mean & $\begin{array}{l}\text { Standard } \\
\text { Deviation }\end{array}$ & Interpretation \\
\hline $\begin{array}{l}\text { IC Inventory } \\
\text { Audit }\end{array}$ & $\begin{array}{l}\text { Involved the identification and recognition of the } \\
\text { intellectual capital in the firm }\end{array}$ & 4.24 & 0.67 & Great Extent \\
\hline $\begin{array}{l}\text { IC Elicitation } \\
\text { Audit }\end{array}$ & $\begin{array}{l}\text { Determined the extent to which the company is able to } \\
\text { draw out IC from individuals or groups of individuals }\end{array}$ & 4.22 & 0.69 & Great Extent \\
\hline $\begin{array}{l}\text { IC Generation } \\
\text { Audit }\end{array}$ & Traced how the company is able to create & 4.20 & 0.87 & Great Extent \\
\hline $\begin{array}{c}\text { IC } \\
\text { Documentation } \\
\text { Audit } \\
\end{array}$ & $\begin{array}{l}\text { Determined the extent to which the company was able to } \\
\text { document }\end{array}$ & 4.27 & 0.79 & Great Extent \\
\hline $\begin{array}{l}\text { IC Utilization } \\
\text { Audit }\end{array}$ & $\begin{array}{l}\text { Evaluated the extent to which the company is able to } \\
\text { apply and handle IC assets }\end{array}$ & 4.18 & 0.86 & Great Extent \\
\hline $\begin{array}{l}\text { IC Retention } \\
\text { Audit }\end{array}$ & $\begin{array}{l}\text { Evaluated the extent to keep the owners of } U \text { in the } \\
\text { organization }\end{array}$ & 4.23 & 0.76 & Great Extent \\
\hline $\begin{array}{l}\text { IC Maintenance } \\
\text { Audit }\end{array}$ & $\begin{array}{l}\text { Evaluated the extent to which the company is able to } \\
\text { preserve and keep its IC assets. }\end{array}$ & 4.38 & 0.77 & Great Extent \\
\hline $\begin{array}{l}\text { IC Enrichment } \\
\text { Audit }\end{array}$ & $\begin{array}{l}\text { Evaluated the extent to which the company is able to } \\
\text { enhance and reinforce IC assets. }\end{array}$ & 4.34 & 0.61 & Great Extent \\
\hline Overall & & 4.26 & 0.747 & Great Extent \\
\hline
\end{tabular}

\begin{tabular}{c|l} 
Rating & \multicolumn{1}{|c}{ Interpretation } \\
\hline 1 & No extent at all \\
2 & Little extent \\
3 & Moderate extent \\
4 & Great extent \\
5 & Very great extent
\end{tabular}

Statistical results in Table I showed that respondents perceived their management to have extended considerable effort in managing intellectual capital with an overall mean of 4.25600 with a standard deviation of 0.74663 . A 4.25 rating scale implied a productive, aggressive and competitive business organization and IC management is being implemented to a great extent. However, there are opportunities that need to be optimized and this presents a challenge to the organization. These findings support the contention that in a creative industry, there is active effort in the management of intellectual capital for it is considered a major contributor to the company's competitive advantage.

Pearson's correlation. The Pearson's correlation coefficient ( $r$ ) was derived to measure the strength of association between and among the variables of the study namely IC inventory audit, elicitation audit, generation audit, documentation audit, utilization audit, retention audit, maintenance audit and enrichment audit. Findings in Table II showed that Pearson's correlation coefficient $(r)$ was very significant with a value that ranged from .958 to .696 between and among the variables.

A closer look on the relationship of the variables revealed significant findings that support the common beliefs and contentions regarding knowledge and its characteristics. From the findings the following can de deduced:

1) IC inventory audit and IC documentation has $r$ with a 
high value of .867 . From the figure it can be implied that once IC is identified there is strong evidence that it is documented upon identification.

2) IC elicitation audit and maintenance has $r$ with a high value of .885 . From the figure it can be implied that once effort to draw out IC from individuals or groups of individuals (knowledge workers) were made then it follow that they are preserved and kept as assets of the company.

3) IC documentation audit and utilization has $r$ with a high value of .958 . From the figure it can be implied that once the IC is documented properly either through efficient access to data or legal registration, then it followed that it was utilized and translated these data into systems, methodologies, functional processes, job enlargement, job enrichment, specific "know-hows" and employee development.

4) IC maintenance audit and enrichment has $r$ with a high value of .893. From the figure it can be implied that if the company is able to preserve and keep its IC assets, it follows that efforts by knowledge leadership for collaboration can be assured.

5) IC inventory audit and IC retention has a relatively low $r$ with a value of .706 compared to the $r$ with the other variables. From the figure it can be implied that although IC is identified, the extent to keep the owners and main contributors (the knowledge workers) of IC is not strong. There is no reliance that they are retained within the business establishment. This supports the contention that knowledge workers naturally move from one organization to another since their value as employees is more dependent on their analytical skills and technical expertise and not on any one company.

6) IC elicitation audit and IC retention has a relatively low $r$ with a value of .696 compared to the $r$ with the other variables. From the figure it can be implied that although efforts were made to draw out from knowledge workers and motivate them to share their knowledge, it does not follow that these knowledge workers, who were the source of IC, can be kept and will remain to work within the company.

7) IC documentation audit and IC retention has a relatively low $r$ with a value of .732 compared to the $r$ with the other variables. From the figure it can be implied that although the company was able to document IC through registration of copyrights, patents, trademarks and trade secrets and /or creation of database, systems and standard information for cross boundary sharing, it does not follow that these knowledge workers, who were the source of IC, can be kept and will remain to work within the company.

8) IC enrichment audit and elicitation has a relatively low $r$ with a value of .784 compared to the $r$ with the other variables. From the figure it can be implied that although the company was able to enhance and reinforce IC assets thru knowledge leadership, synergistic collaboration and cutting edge training, it does not follow that they can easily draw out from knowledge workers and motivate them to share their knowledge.

TABLE II: PEARSON's CORRELATION OF IC SySTEMS AUdiT N=25

\begin{tabular}{|c|c|c|c|c|c|c|c|c|c|}
\hline \multicolumn{10}{|c|}{ Correlations } \\
\hline & & $\begin{array}{c}\text { IC Inventory } \\
\text { Audit }\end{array}$ & $\begin{array}{l}\text { IC Elicitation } \\
\text { Audit }\end{array}$ & $\begin{array}{l}\text { IC Generation } \\
\text { Audit }\end{array}$ & $\begin{array}{c}\text { IC } \\
\text { Document } \\
\text { ation Audit }\end{array}$ & $\begin{array}{l}\text { IC Utilization } \\
\text { Audit }\end{array}$ & $\begin{array}{l}\text { IC Retention } \\
\text { Audit }\end{array}$ & $\begin{array}{c}\text { IC } \\
\text { Maintenance } \\
\text { Audit }\end{array}$ & $\begin{array}{l}\text { IC Enrichment } \\
\text { Audit }\end{array}$ \\
\hline \multirow[t]{3}{*}{ IC Inventory Audit } & Pearson Correlation & 1 & $.851^{\star *}$ & $.763^{\star *}$ & $.867^{* *}$ & $.791^{\star *}$ & $.706^{* *}$ & $.853^{\star \star}$ & $.785^{\star *}$ \\
\hline & Sig. (2-tailed) & & .000 & .000 & .000 & .000 & .000 & .000 & .000 \\
\hline & $\mathrm{N}$ & 25 & 25 & 25 & 25 & 25 & 25 & 25 & 25 \\
\hline \multirow[t]{3}{*}{ IC Elicitation Audit } & Pearson Correlation & $.851^{\star *}$ & 1 & $.808^{\star *}$ & $.848^{\star \star *}$ & $.775^{\star *}$ & $.696^{* *}$ & $.885^{\star \star}$ & $.784^{\star \star}$ \\
\hline & Sig. (2-tailed) & .000 & & .000 & .000 & .000 & .000 & .000 & .000 \\
\hline & $\mathrm{N}$ & 25 & 25 & 25 & 25 & 25 & 25 & 25 & 25 \\
\hline \multirow[t]{3}{*}{ IC Generation Audit } & Pearson Correlation & $.763^{\star \star}$ & $.808^{\star *}$ & 1 & $.887^{\star *}$ & $.804^{\star \star *}$ & $.732^{\star \star}$ & $.811^{\star *}$ & $.789^{\star \star}$ \\
\hline & Sig. (2-tailed) & .000 & .000 & & .000 & .000 & .000 & .000 & .000 \\
\hline & $\mathrm{N}$ & 25 & 25 & 25 & 25 & 25 & 25 & 25 & 25 \\
\hline \multirow[t]{3}{*}{ IC Documentation Audit } & Pearson Correlation & $.867^{\star *}$ & $.848^{\star *}$ & $.887^{\star *}$ & 1 & $.958^{\star *}$ & $.908^{* *}$ & $.942^{\star *}$ & $.872^{\star *}$ \\
\hline & Sig. (2-tailed) & .000 & .000 & .000 & & .000 & .000 & .000 & .000 \\
\hline & $\mathrm{N}$ & 25 & 25 & 25 & 25 & 25 & 25 & 25 & 25 \\
\hline \multirow[t]{3}{*}{ IC Utilization Audit } & Pearson Correlation & $.791^{\star \star}$ & $.775^{\star \star}$ & $.804^{\star *}$ & $.958^{\star \star}$ & 1 & $.954^{* *}$ & $.895^{* \star}$ & $.808^{\star \star}$ \\
\hline & Sig. (2-tailed) & .000 & .000 & .000 & .000 & & .000 & .000 & .000 \\
\hline & $\mathrm{N}$ & 25 & 25 & 25 & 25 & 25 & 25 & 25 & 25 \\
\hline \multirow[t]{3}{*}{ IC Retention Audit } & Pearson Correlation & $.706^{\star *}$ & $.696^{\star *}$ & $.732^{* *}$ & $.908^{\star *}$ & $.954^{\star *}$ & 1 & $.819^{\star \star}$ & $.816^{\star *}$ \\
\hline & Sig. (2-tailed) & .000 & .000 & .000 & .000 & .000 & & .000 & .000 \\
\hline & $\mathrm{N}$ & 25 & 25 & 25 & 25 & 25 & 25 & 25 & 25 \\
\hline \multirow[t]{3}{*}{ IC Maintenance Audit } & Pearson Correlation & $.853^{\star \star}$ & $.885^{\star \star}$ & $.811^{* *}$ & $.942^{\star \star}$ & $.895^{\star \star}$ & $.819^{\star *}$ & 1 & $.893^{\star \star}$ \\
\hline & Sig. (2-tailed) & .000 & .000 & .000 & .000 & .000 & .000 & & .000 \\
\hline & $\mathrm{N}$ & 25 & 25 & 25 & 25 & 25 & 25 & 25 & 25 \\
\hline \multirow[t]{3}{*}{ IC Enrichment Audit } & Pearson Correlation & $.785^{\star \star}$ & $.784^{\star \star}$ & $.789^{\star \star *}$ & $.872^{\star \star}$ & $.808^{\star \star}$ & $.816^{* \star}$ & $.893^{\star \star}$ & 1 \\
\hline & Sig. (2-tailed) & .000 & .000 & .000 & .000 & .000 & .000 & .000 & \\
\hline & $N$ & 25 & 25 & 25 & 25 & 25 & 25 & 25 & 25 \\
\hline
\end{tabular}

**. Correlation is significant at the 0.01 level (2-tailed).

Valuation of Intellectual Capital. The study aimed to determine how the creative enterprises value IC and an evidence of valuation is the financial statement and/or other reports that highlight valuation. Findings in Table III showed that 8 or $32 \%$ of the company respondents reported their intellectual capital as intangible assets and 17 or $68 \%$ reported them as expense. Important to note is that these 8 respondents were those that signified they have in possession patent certificates and design rights. This finding validated the accounting practice of the company where intangible asset must satisfy the identifiability criteria which is: the asset is capable of being separated or divided from the entity and sold, transferred, licensed, rented or exchanged, either individually or together with a related contract, asset or liability; or the asset arose from contractual or other legal rights. 
Further probing on the valuation method used revealed the following findings:

1) Intellectual property rights are the only items that would last through the years. Human asset, market assets and infrastructure assets should be reported as cost. They are susceptible to obsolescence where they become old-fashioned and no longer useful after a period of time.

2) They are difficult to separate the related expenses to the item and

3) They do not comply with the identifiability criteria of IAS \# 38 thus giving the company documentation problems.

Findings in Table III also showed that three respondents were not satisfied with traditional financial statements in the manner of reporting IC. They were reporting IC as expense and they admit they were uncomfortable with the procedures. Unfortunately, they could not give any alternative manner for reporting as there are more pressing issues in the company that need their attention. This seeming dissatisfaction validates the literature findings that there is a growing frustration with traditional financial reporting because it is incapable of explaining "new" resources such as relationships, internally generated assets and knowledge [3]. The challenge was attributable to the lack of tangible collaterals to measure intangible assets [7].

TABLE III: VALUATION OF INTELLECTUAL CAPITAL $N=25$

\begin{tabular}{|c|c|c|}
\hline Reported in Financial Statements & Frequency & Percent \\
\hline Yes, reported as Intangible Asset & 8 & 32 \\
\hline Yes, reported as Expense & 17 & 68 \\
\hline Total & 25 & 100 \\
\hline Satisfaction of Traditional Financial Statements in Reporting Intellectual Capital & Frequency & Percent \\
\hline Yes & 22 & 88 \\
\hline No & 3 & 12 \\
\hline Total & 25 & 100 \\
\hline Other Reports to Supplement IC Valuation & Frequency & Percent \\
\hline Sales Reports (i.e. by product line) & 4 & 16 \\
\hline Product performance ledger & 2 & 8 \\
\hline no other reports done & 9 & 36 \\
\hline no answer & 10 & 40 \\
\hline Total & 25 & 100 \\
\hline Adherence to BIR Reporting Policies & Frequency & Percent \\
\hline Yes & 25 & 100 \\
\hline No & 0 & 0 \\
\hline Total & 25 & 100 \\
\hline
\end{tabular}

All of the respondents complied with the financial reporting requirements of the Bureau of Internal Revenue (BIR) of the Philippine government. BIR is the government agency that is tasked to collect taxes from business establishment. Assessment of taxes to be paid is based on financial statements duly submitted to its office. Data also showed that market assets, human assets and infrastructure assets are reported as expense and intellectual property rights as intangible assets in the financial statement.

Intellectual Capital and Business Performance. The study hypothesized that knowledge, in the form of intellectual capital, has a direct relationship with the firm's business performance. This is consistent with the business characteristic of the third millennium's economy as knowledge based and it is knowledge that can provide a sustainable competitive advantage to the firm.

The study sought the relationship of intellectual capital and business performance by asking the respondents' perception of the relationship. The respondents were asked of their perception on the improvement felt on business performance attributable to intellectual capital for the past two years. To do this, a likert scale response was used. In the scale of 1 to 3 , the respondents were asked to rate the degree of the improvement felt. Improvement is rated to be minor if intellectual capital's contribution is less than $20 \%$ felt contribution and major improvement if more than $20 \%$ felt contribution.

More importantly, the study sought to find out which component of intellectual capital namely market asset, human asset, infrastructure and intellectual property rights has more impact or more significance to business performance.

Findings in Table IV showed that intellectual property right with a rating scale of " 3 " and human asset with a rate of " 2.84 " implied that both provided major improvements on business performance. On the other hand, market assets with a rate of " 2.16 " and infrastructure assets at " 1.88 " implied that it contributed minor improvements on business performance.

The researcher probed on the justification for such a rating through an in-depth interview with the respondents. The findings revealed very interesting results. For the 11 company respondents who claimed not to have any intellectual property rights and, at the time of interview, do not possess anything unique or distinctly original, human capital was deemed to be the most important and a main contributor to the company's business performance. The human assets possess skills that are vital to the business and are what marks the company's competitive advantage. There is a remarkable reliance on the creative worker and on their output. Examples of this are company respondents from the 
following clusters: photography, theater and performing art, visual arts and music.

TABLE IV: INTELLECTUAL CAPITAL AND IMPROVEMENT ON BUSINESS

\begin{tabular}{|c|c|c|}
\hline \multicolumn{3}{|c|}{ PERFORMANCE } \\
\hline $\begin{array}{c}\text { Type Of IC } \\
\text { Asset }\end{array}$ & Scale & Interpretation \\
\hline $\begin{array}{l}\text { Intellectual } \\
\text { Property } \\
\text { Rights }\end{array}$ & 3.00 & Major Improvement (more than 20\%) \\
\hline Human Asset & 2.84 & Major Improvement (more than 20\%) \\
\hline Market Asset & 2.16 & Minor Improvement (less than 20\%) \\
\hline $\begin{array}{l}\text { Infrastructure } \\
\text { Asset }\end{array}$ & 1.88 & Minor Improvement (less than 20\%) \\
\hline
\end{tabular}

\begin{tabular}{c|l}
\hline Rating & \multicolumn{1}{|c}{ Interpretation } \\
\hline 0 & None; no possession of this asset \\
1 & No improvement \\
2 & Minor improvement (less than 20\%) \\
3 & Major improvement (20\% or more)
\end{tabular}

Infrastructure asset area important but have limitations that must be taken note of: fast pace of technological improvement; machines and equipment become obsolete sooner than expected due to new models and new features are always available in the market; easy accessibility to new machines and new technologies; any company can purchase it and use it in the business. These insights came from company respondents from the following clusters: photography, design, photography, architecture, new media and music.

Market assets, particularly a distinct brand, customers' loyalty and distribution channel are important but it must be supported by quality products. If the product diminishes in quality (including uniqueness of design) then the market assets also diminish in importance. These insights came from company respondents from the following clusters: design, photography, architecture, new media and music. These finding supports the contention that the knowledge workers, their interaction and their outputs are the main source of a company's competitive advantage in the creative industry. Infrastructure assets such as technology are enablers in the creation process of knowledge. Market assets are outputs of the interaction between human asset and infrastructure asset.

The CGA Knowledge Flow Management in the Creative Enterprise. The premise of the study is that a knowledge management system (KMS) must be embedded in a firm in order for knowledge to be developed to its potentials and contribute to business performance. It would be this system that would help guide the flow of knowledge.

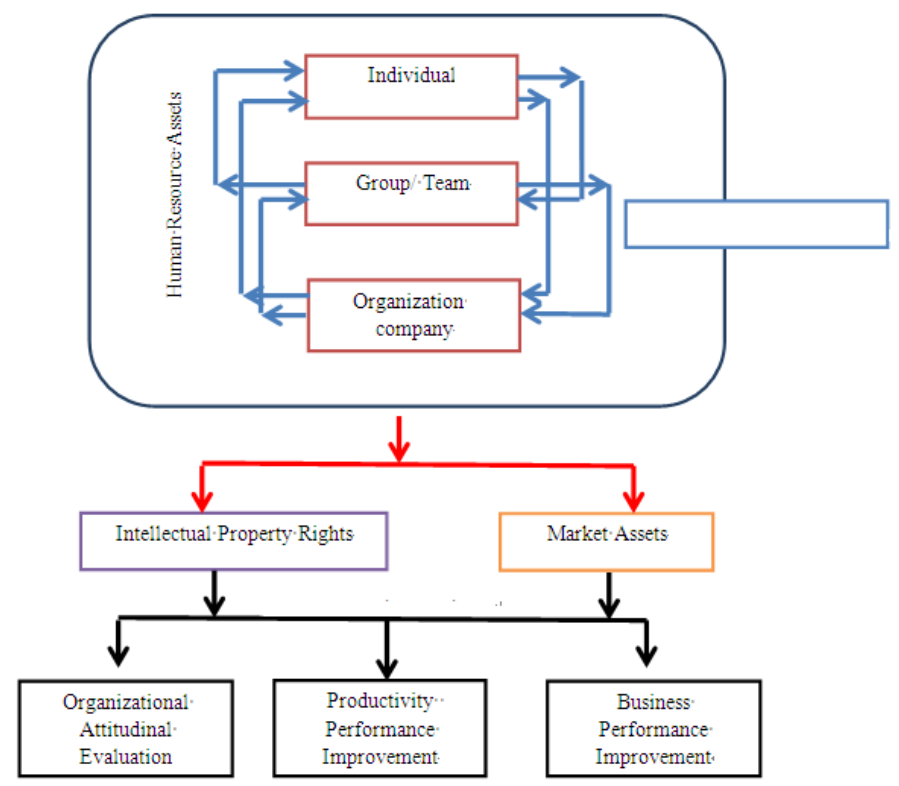

Fig. 2. The CGA knowledge flow management model for the creative industries.

Fig. 2 is the CGA Knowledge Management System model recommended for the creative enterprises in Metropolitan Cebu, Philippines. The model used the input-process-output framework and is the fruit of the findings of the study and the various literatures read. CGA is the acronym of the researcher's name.

The word "flow" was intentionally included to adhere to the claim of Leistner that the thing that to be managed is the flow of knowledge [8]. It can be speeded up by the provision of tools and technology as a foundation or the creation of an environment conducive for sharing. The proposed model shows that what is being managed is the direction of knowledge and not of knowledge itself. The core objective of the model then is to ensure knowledge transfer.

The inputs. Intellectual capital is sub-divided into components namely market assets, human resource assets, infrastructure assets and intellectual property rights. This is to emphasize the need to classify intellectual capital since each component has its distinct characteristic.

The heart and focus of the model is the human resource assets from where knowledge emanates or springs from. Findings showed that human resource was the most important and volatile among intellectual capital assets. Human resource assets refer to the employees' expertise, personal qualities and traits of employees, managerial and entrepreneurial skills of the middle and top management. This recognizes that tacit knowledge begins with the individual.

The model sub divides human resources to three groups: the individual, the team/group and the organization. The human resource asset starts from the individual, the knowledge worker, who is assumed to be valuable to the 
company because of his technical expertise, creative talents and/or entrepreneurial skills. He is the source of knowledge as well as the creator of new knowledge.

The groups or teams are from where the individual directly interacts with. The third group is the organization from where the teams will interact with one another through the exchange of knowledge. This is to emphasize collaboration among different fields of expertise coming from different departments. A holistic approach to the creation of a product or a new process is necessary. In order to drive this point down, the three levels of human resources must be recognized. The systems review would also be an opportunity to discover duplication of work in departments and discuss how it can be stopped or merged.

Infrastructure asset is the big square that encompasses the human resource asset. Infrastructure assets are the quality standards practices and technology acquired. Findings showed that although infrastructure is important, it is seen more as an enabler to the creation of knowledge. The role of the infrastructure asset is to facilitate the flow of knowledge.

The Process. The process flow is designated by the lines moving along the variables of the model. There are distinct colors used for the different levels of the process flow. The direction of the arrow head shows the source $\longrightarrow$ and receiver $\longleftarrow$ of the flow.

The blue lines represent the interaction among the three levels of human resource assets: the individual, group/team and the organization. The interaction does not follow a specific direction. Communication line is kept open such that the individual can go directly to the other departments. There is minimal protocol observed as to rank and position in the exchange of knowledge. Emphasis here is not the face to face interaction but the flow of communication within the company and among its branches.

The interaction of the infrastructure asset and human resource asset is represented by the red lines which would lead to the production of intellectual property rights and market assets.

The interaction of the four intellectual components is represented by the black lines where it is supposed to contribute to the improvement of business performance.

The output. The output will emanate from the interaction of the four components of intellectual capital. The areas for audit are the following: organizational attitude, business performance and productivity performance.

The Working Environment. The proposed model is believed to produce an effective collaboration and communication within the business organization which is what a creative enterprise needs. But for the model to function to its maximum level the following are necessary pre-requisites .a knowledge-sharing culture that is ingrained in the management and staff; the sharing must reach up to reciprocity; collaborative work spaces must be in place to create an environment conducive to sharing.

The knowledge-sharing culture refers to the individual's willingness to share what he has to others in an unselfish manner. This means to share without asking or waiting for something. The knowledge-sharing initiative must start from the individual. This culture is inspired by the Focolare Movement where the style and idea of governance lies in living and nourishing "continual mutual love" [9].
The sharing must reach up to reciprocity. The main task of the model is to create new knowledge. To do that the knowledge that is shared must be refined, added on or improved. For the knowledge worker to continue on with the participation in this quest for sharing, then he must be able to give up to the point where the recipient of his deed will be so convinced of this act of sharing that he is unconsciously compelled to share as well. This "sharing attitude" is passed on up to a point that the initial source of knowledge becomes a recipient of new knowledge. From his unselfish sharing, he gains new knowledge.

Collaborative work spaces must be in place to create an environment conducive to sharing. Motivating people to share is very difficult. Demotivated people or passivity can be a barrier to the flow of knowledge. The researcher advocates for subtle ways to encourage sharing from people. Interaction would naturally flow in a work place that is conducive to collaboration.

This calls for a paradigm shift in the way of thinking of knowledge owners who is seen as the source of creativity and competitive advantage for the firm.

\section{CONCLUSIONS}

The findings validated knowledge management concepts and enabled the study to use research outputs at the service of the creative industry.

The concept of Intellectual Capital was better understood when it was broken down into four components namely: market assets, human resource assets, infrastructure assets and intellectual property rights.

Human resource asset was the most valuable component of intellectual capital in relation to the characteristics of the creative industry. Creativity starts with the individual or groups of individuals. Infrastructure assets are mere enablers to the knowledge flow.

Intellectual capital has contributed to an improvement in business performance, productivity performance and to attitudinal change of the organization.

The systems audit revealed that elicitation, generation, maintenance and preservation of intellectual capital are highly correlated (a strong association is measured). The retention of intellectual capital generated a low correlation value which implies that even if management of intellectual capital is in place and well done, it does not ensure the retention of the knowledge workers in the company.

The CGA KFM model is a valuable tool to the management of knowledge is a creative enterprise for the following reasons: It takes into account the intricacies of the creative industry, its distinct characteristics and normal tendencies; It focuses on the key players of the enterprise, their strength and weaknesses and shows their relationship with one another; It serves as a decision tool for management; It emphasizes the role of managers as facilitators and not controllers of the knowledge flow in the KMS; It presents an alternative view in the valuation of intellectual capital; It emphasizes that it is the flow of knowledge that is being managed and not knowledge in itself.

The culture of sharing and the concept of reciprocity in sharing are pre-requisites to a successful implementation of knowledge transfer within a business establishment. This 
calls for a 360 degree change in in the work attitude of the knowledge owners.

\section{REFERENCES}

[1] A. Brooking, Intellectual Capital: Core Asset for the Third Millennium Enterprise, U.K: International Thomson Business Press, 1996.

[2] M. Jr. L. Rafael, Fundamentals of Accounting, 2002.

[3] J. Mouritsen, P. N. Bukh, and B. Marr, "Reporting on intellectual capital: why, what and how?" Measuring Business Excellence, vol. 8 , no. 1 , pp. 46-54, 2004.

[4] P. O'Reagan, D. O'Donnel, T. Kennedy, N. Bontis, and P. Cleary, "Board composition, non-executive directors, and governance cultures in Irish ICT firms," Corporate Governance: International Journal of Business in Society, vol. 5, no. 4, pp. 56-63, 2005.

[5] R. B. Gallupe. (2000). Knowledge Management Systems: Surveying the Landscape. [Online]. Available: http://citeseerx.ist.psu.edu/viewdoc/download?doi=10.1.1.104.7777 \&rep=rep $1 \&$ type $=$ pdf

[6] F. C. Young, Intellectual Capital Management: A Competitive Asset in the $3^{\text {rd }}$ Millennium, Philippines: Bright Minds Publishing House Philippines, 2004.

[7] G. Kristandl and N. Bontis, "Defining intangible assets and intellectual capital," Management Decision, vol. 45, no. 9, pp. 1510-1524, 2007

[8] F. Leistner, Mastering Organizational Knowledge Flow: How to Make Knowledge Sharing Work, New Jersey: John, Wiley \& Sons, 2010.

[9] C. Lubich, Christian Living Today, United States: New City Press, 1997.

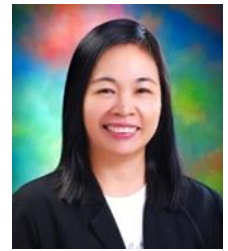

Corazon G. Anzano is the chair of the department of economics of the University of San Carlos (USC), Cebu, Philippines. She completed her undergraduate business administration program major in Economics and master of arts in economics in same University. She finished her Doctor of Philosophy in Management in October 2012. Her book entitled Students Entrepreneurs' Journey A Casebook on Student Business Enterprises (which she co-authored with Dr. Khanser) published by the USC Press, is used as a major reference in the undergraduate business program of USC. Her research interest includes knowledge management, entrepreneurship and marketing.

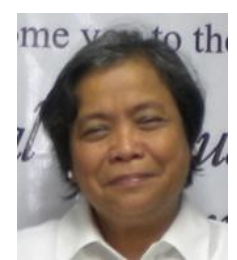

Marites A. Khanser is the research coordinator of the School of Business and Economics. She finished a doctor of business administration (DBA) degree from De La Salle University in Manila, Philippines in 1998. She holds an MA in English Language (UP-Diliman) in 1991 and an MBA (Xavier University, Ateneo de Cagayan) in 1989. Before joining USC, she was a full time faculty of the John Gokongwei School of Management, Loyola Schools, Ateneo de Manila University. She is the author of the best-selling entrepreneurship book, John L. Gokongwei Jr: The Path of Entrepreneurship, published by Ateneo de Manila University in 2007. She has written a total of 15 books that have been published through the years. 